SARAH MERÇON-VARGAS

\title{
MEIOS ALTERNATIVOS NA RESOLUÇÃO DE CONFLITOS DE INTERESSES TRANSINDIVIDUAIS
}

\author{
MESTRADO EM DIREITO
}

ORIENTADOR: PROF. DR. RICARDO DE BARROS LEONEL

FACULDADE DE DIREITO DA UNIVERSIDADE DE SÃO PAULO SÃO PAULO

2012 


\section{MEIOS ALTERNATIVOS NA RESOLUÇÃO DE CONFLITOS DE INTERESSES TRANSINDIVIDUAIS}

Dissertação apresentada como requisito parcial à obtenção do título de Mestre em Direito, no Programa de Pós-Graduação Stricto Sensu em Direito Processual, da Faculdade de Direito da Universidade de São Paulo.

Orientador: Prof. Dr. Ricardo de Barros Leonel 


\title{
TERMO DE APROVAÇÃO
}

\author{
SARAH MERÇON-VARGAS
}

\section{MEIOS ALTERNATIVOS NA RESOLUÇÃO DE CONFLITOS DE INTERESSES COLETIVOS}

Dissertação aprovada como requisito parcial para a obtenção do grau de Mestre em Direito, no Programa de Pós-Graduação Strictu Sensu em Direito Processual, da Faculdade de Direito da Universidade de São Paulo, pela seguinte Banca Examinadora:

Orientador: $\quad$ Professor Doutor Ricardo de Barros Leonel

Departamento de Direito Processual - USP

Membros: $\quad$ Prof. Dr.

Prof. Dr.

São Paulo, de de 2012. 


\section{RESUMO}

O presente trabalho destina-se a examinar as perspectivas ao uso de meios extrajudiciais de resolução de conflitos para a composição de conflitos coletivos no Brasil. Para tanto, serão analisadas as principais características da negociação, mediação, conciliação e arbitragem, identificados os requisitos de admissibilidade para o uso de tais técnicas e explicitados os elementos a serem considerados no exame de adequação do uso de meios extrajudiciais. Além disso, serão examinadas as principais características dos direitos difusos, coletivos stricto sensu e individuais homogêneos, assim como as regras processuais pertinentes à legitimação e coisa julgada no processo coletivo. Mais adiante, o presente trabalho tentará sistematizar hipóteses sobre o cabimento e sobre a adequação das técnicas extrajudiciais para a resolução de conflitos que envolvem direitos coletivos. Ao final, será possível concluir que tais direitos podem e devem ser resolvidos por meio de técnicas extrajudiciais, em especial por meio da negociação, da conciliação e da arbitragem.

Palavras-chave: meios adequados de resolução de controvérsias, negociação, mediação, conciliação, arbitragem, arbitrabilidade, direitos coletivos, direitos difusos, direitos coletivos stricto sensu, direitos individuais homogêneos, compromisso de ajustamento de conduta, transação. 


\begin{abstract}
The following work aims at examining prospects in the use of alternative dispute resolution techniques in Brazilian class actions. To this end, it will, at first, analyze negotiation, mediation, conciliation and arbitration main characteristics. Also, admission criteria for each of these dispute resolution techniques will be identified and the elements that should be considered for the adequacy exam will be outlined. Further on, the three kinds of Brazilian class action and the main characteristics of each class procedures will be examined, with special concern to procedure laws pertaining legitimacy and res judicata. Moreover, the paper will systematically study the hypothesis in which extrajudicial conflict resolution techniques may be applied and the adequacy of their use in cases encompassing collective rights. Finally, in its conclusion, it will be demonstrated that extrajudicial techniques can be used to solve conflicts involving collective rights, mainly through negotiation, conciliation and arbitration.
\end{abstract}

Keywords: alternative dispute resolution, negotiation, mediation, conciliation, arbitration, arbitrability, class actions, mandatory class action, class action for damages, settlement. 


\section{CAPÍTULO I - INTRODUÇÃo}

\section{O tema e suas limitações}

É notório o esforço da doutrina processual contemporânea em abandonar o fetichismo pela jurisdição estatal ${ }^{1}$ e expandir, no plano do movimento universal de acesso à justiça, a utilização de mecanismos extrajudiciais ${ }^{2}$ de resolução de conflitos.

Na busca por resultados mais efetivos, a tendência de universalizar a tutela jurisdicional evidencia, de um lado, a urgência em se aprimorar a técnica processual e, de outro, a necessidade de se ampliar as formas de acesso à justiça, para além da técnica universal do processo estatal.

Em clássica construção sobre ADR (Alternative Dispute Resolution), Marc GALANTER assinala que a utilização de técnicas de resolução de conflitos deve se orientar por $(i)$ argumentos de produção, voltados à obtenção de resultados com menor dispêndio de tempo e de recursos, e por (ii) argumentos de qualidade, que denotam os benefícios que a utilização de um dado mecanismo pode trazer. ${ }^{3}$ Esta linha de pesquisa vem ao encontro da necessidade de se buscar soluções alternativas, em especial, diante da

1 A expressão é de Candido Rangel DINAMARCO (Tutela Jurisdicional. Fundamentos do Processo Civil Moderno. 6. ed. São Paulo: Malheiros, 2010, v. II, p. 392). O mesmo fenômeno foi também observado e referido por Kazuo WATANABE como a cultura da sentença, que cede lugar à cultura da pacificação (A mentalidade e os meios extrajudiciais de solução de conflitos. In: GRINOVER, Ada Pellegrini. WATANABE, Kazuo; LAGRASTA NETO, Caetano (coord.). Mediação e Gerenciamento do Processo. São Paulo: Atlas, 2008, p. 7 e 10); por Rodolfo de Camargo MANCUSO, que alude à cultura demandista ou judiciarista (A resolução dos conflitos e a função judicial. São Paulo: RT, 2010, p. 12 e 36, respectivamente) e ainda, por Alexandre Amaral GAVRONSKI sob a rubrica de lógica judicialiforme (Técnicas Extraprocessuais de tutela coletiva: a efetividade da tutela coletiva fora do processo judicial. São Paulo: RT, 2010, p. 46).

2 Como adverte Rodolfo de Camargo MANCUSO, o termo alternativo, de origem na expressão norteamericana Alternative Dispute Resolution, contraria a ordem cronológica dos eventos na história, uma vez que foi justamente a justiça estatal que adveio como um posterious à autotutela e, portanto, como alternativa à forma até então primordial de resolução de litígios. (A resolução..., p. 49). Para além do aspecto anacrônico da terminologia, Paula Costa e SILVA faz outra crítica interessante ao emprego da expressão alternativa. Segundo a Autora, a ideia de alternatividade somente poderia ser utilizada se houvesse livre escolha entre meios de resolução de disputas funcionalmente equivalentes. Todavia, como a justiça pública não é nem sempre acessível e nem sempre eficiente, a conclusão é que as técnicas ditas alternativas acabam por ser muitas vezes necessárias e inevitáveis. (A Nova Face da Justiça: os meios extrajudiciais de resolução de controvérsias. Lisboa: Coimbra Editora, 2009, p. 35-37).

3 GALANTER, Marc. Introduction: Compared to what? Assessing the quality of dispute processing. Denver University Law Review, n. 66, 1989, p. xii. Em doutrina nacional, esses argumentos foram bem desenvolvidos por Carlos Alberto de SALLES (Execução judicial em matéria ambiental. São Paulo: RT, 1998, p. 35). 
ineficácia dos mecanismos processuais tradicionalmente utilizados para dirimir os novos conflitos, em perfil e em escala ${ }^{4}$, que caracterizam a sociedade pós-moderna. ${ }^{5}$

No contexto deste novo perfil litigioso, destacam-se, por numerosidade e relevância social, os conflitos de feição transindividual.

De fato, os contornos massificados das relações intersubjetivas peculiares deste novo tempo, aliados à ampliação do horizonte de pretensões jurisdicionalizáveis ${ }^{6}$ criaram um contingente de demandas que supera, em muito, a capacidade da estrutura judiciária $^{7}$. Ademais, a qualidade dos resultados obtidos por intermédio apenas da técnica estatal de resolução de conflitos, é questionável.

Assim, a confluência de tais circunstâncias recomenda a investigação teórica acerca da aptidão dos conflitos coletivos para serem solucionados por intermédio de técnicas não judiciais de resolução de controvérsias.

A opção pelo especial direcionamento da abordagem às demandas coletivas deriva da constatação de que os conflitos sociais de massa - demandas coletivas lato sensu em potencial, principalmente sob a égide da categoria dos direitos individuais homogêneos - constituem relevante parcela dos litígios da sociedade contemporânea ${ }^{8}$. Mesmo as demandas que ordinariamente não são movidas como ações coletivas, acabam por sofrer processos de coletivização no poder judiciário, como é o caso do mecanismo processual de julgamento de recurso especial repetitivo por amostragem ${ }^{9}$.

Além disso, diante do atual processo de formação de um novo paradigma de direito, mais adaptado à complexidade social da pós-modernidade, de que trata Alexandre

FARIA, José Eduardo. O Direito na economia globalizada. São Paulo: Malheiros, 2004, p. 7-8.

5 Alexandre Amaral GAVRONSKI assinala inclusive a necessidade de se assimilar um novo paradigma de direito, distinto da concepção original de Estado de Direito, mais adaptado à crescente complexidade social deste século. Esse novo paradigma teria como características principais a dessubstantivação, a informalidade e a participação (Técnicas..., p. 46 e 55).

6 DINAMARCO, Candido Rangel. Universalizar a Tutela Jurisdicional. Fundamentos do Processo Civil Moderno. São Paulo: Malheiros, 2010, v. I, p. 396.

7 LEONEL, Ricardo de Barros. Manual do Processo Coletivo. São Paulo: RT, 2002, p. 96.

8 CAPPELlETTI, Mauro. Os métodos extrajudiciais de solução de conflitos no quadro do movimento universal do acesso à justiça. Revista de Processo, ano 19, n. 74, abr-jun 1994, p. 84.

9 Baseado no procedimento modelo alemão (mustervenfahren), Antonio do Passo CABRAL traz interessante proposta de forma alternativa (não representativa) de tutela coletiva, consistente na formação de incidente de coletivização de questões comuns a inúmeras pretensões individuais [O novo procedimento-modelo (Musterverfahren) alemão: uma alternativa às ações coletivas. Revista de Processo, ano 32, n. 147, maio-2007]. 
Amaral GAVRONSKI, passa a ser enfrentar o profundo enlaçamento entre o processo coletivo e a jurisdição estatal, justamente para testar sua necessariedade ${ }^{10}$ e seus limites.

De fato, o Estado, antes o principal provedor de acesso aos direitos fundamentais, tais como o direito à saúde e o direito à educação, cedeu espaço considerável à iniciativa privada nas últimas décadas.

Atualmente, boa parte da população praticamente não mais utiliza o serviço público de saúde, diante do espaço que veio a ser ocupado pelos planos e hospitais particulares de saúde. Isso não significa, porém, que o Estado não tenha que prestar tais serviços, caso venha a ser demandado.

O mesmo fenômeno pode ser verificado no âmbito da educação voltada para o ensino superior. Se antes o serviço era ofertado apenas pelas universidades e por poucas instituições privadas, atualmente, o setor privado desempenha inegavelmente papel primordial na prestação deste mesmo serviço.

Além desses, outros exemplos poderiam ser dados. O fato é que é preciso perceber, neste contexto, que o Estado brasileiro, na pós-modernidade, tem reconhecido a sua absoluta insuficiência enquanto prestador de serviços.

É exatamente este contexto que inspira a investigação teórica sobre a necessariedade do Poder Judiciário, especialmente em relação às demandas coletivas, em que são veiculadas pretensões ligadas à realização do interesse público ou, no mínimo, pretensões de grande interesse social.

Não se ignora a forte resistência que paira sobre o assunto, especialmente em razão $(i)$ da nota de indisponibilidade - ainda que sem uma definição adequada - que se atribui aos direitos coletivos, (ii) do interesse público que orienta a sua efetivação e (iii) dos esquemas peculiares de legitimação caracterizam a tutela coletiva. Todavia, na esteira do atual estágio teórico do movimento de acesso à justiça, esses temas devem ser enfrentados, especialmente para que seja avaliado o grau de dependência dos conflitos coletivos em relação ao Poder Judiciário.

Há ainda uma razão de ordem pragmática que justifica o enfrentamento do tema proposto: muitos litígios que envolvem direitos coletivos efetivamente são resolvidos

10 TALAMINI, Eduardo. A arbitragem e a parceria público-privada (PPP). In: TALAMINI, Eduardo; JUSTEN, Monica Spezia. Parcerias Público-Privadas. São Paulo: RT, 2005, p. 342-343. 
por compromissos de ajustamento de conduta e ou por acordos entabulados em processos judiciais, após ampla negociação entre o Parquet e os particulares envolvidos. ${ }^{11}$

A verdade, portanto, é que existe, na prática, resolução extrajudicial de conflitos coletivos $^{12}$, sem que, haja, contudo, lastro teórico correspondente para dar suporte às diversas questões jurídicas imbricadas nesta complexa tarefa.

Além disso, a proposta legislativa de alteração da Lei da Ação Civil Pública (Projeto de Lei n. $\left.{ }^{\circ} 5.139 / 2009\right)^{13}$ contempla em seus artigos $19^{14}$ e 57 , parágrafo $4^{\text {o15 }}$ a possibilidade de resolução extrajudicial de conflitos que envolvam direitos coletivos, o que também recomenda a investigação teórica do tema.

É preciso pontuar, de antemão, que, diante do objetivo específico e restrito desta dissertação, a investigação a ser desenvolvida irá concentrar-se na face processual da questão, apesar de ser também profunda a ligação do tema com o exame do direito material subjacente aos litígios coletivos. ${ }^{16}$

11 A afirmação não tem base estatística, já que não se tem notícia de pesquisa que pudesse demonstrar tal fato empiricamente. Todavia, Paulo de Bessa ANTUNES também observa e destaca o mesmo fenômeno (Direito ambiental, indisponibilidade de direitos, solução alternativa de conflitos e arbitragem. Revista de Arbitragem e Mediação, v. 30, jul. 2011, p. 103).

12 “(...) a realidade sobrepôs-se a teoria. O tempo se encarregou de mostrar que conciliar é melhor que julgar, desde que no acordo fique respeitada e bem delimitada a proteção do meio ambiente. Poupam-se tempo, provas caras e complexas, bem como execuções nem sempre bem sucedidas. Atualmente, com nomes variados, celebram-se acordos nos inquéritos civis instaurados pelo Ministério Público (Lei 7.347, de 1985, artigo $5^{\circ}$, parágrafo $6^{\circ}$ ), nos processos administrativos instaurados pelos órgãos ambientais (Lei 7.347, de 1985, artigo 5\%, parágrafo6 ${ }^{\circ}$, e Lei 9.605, de 1988, artigo 72, parágrafo4 ${ }^{\circ}$, e Dec. 6.514, de 2008, artigo 143) (...)" (FREITAS, Vladimir Passos de; FREITAS, Mariana Almeida Passos de. Conciliação, execução e efetividade nas ações civis públicas. In: MILARÉ, Édis. A ação civil pública após 25 anos. São Paulo, RT, 2010, p. 830).

13 O Projeto de Lei n. ${ }^{\circ}$ 5.139/2009 foi rejeitado pela Comissão de Constituição da Câmara dos Deputados. Houve recurso para o Plenário, mas, sem que haja pedido de retomada, o projeto será arquivado.

14 “Art. 19. Não sendo o caso de julgamento antecipado, encerrada a fase postulatória, o juiz designará audiência preliminar, à qual comparecerão as partes ou seus procuradores, habilitados a transigir. $\$ 1^{o}$ O juiz ouvirá as partes sobre os motivos e fundamentos da demanda e tentará a conciliação, sem prejuízo de outras formas adequadas de solução do conflito, como a mediação, a arbitragem e a avaliação neutra de terceiro, observada a natureza disponível do direito em discussão. $\S 2^{\circ}$ A avaliação neutra de terceiro, de confiança das partes, obtida no prazo fixado pelo juiz, é sigilosa, inclusive para este, e não vinculante para as partes, tendo por finalidade exclusiva orientá-las na tentativa de composição amigável do conflito. $\$ 3^{\circ}$ Quando indisponível o bem jurídico coletivo, as partes poderão transigir sobre o modo de cumprimento da obrigação. $\$ 4^{\circ}$ Obtida a transação, será ela homologada por sentença, que constituirá título executivo judicial”

15 “Art. 57. O demandado, a qualquer tempo, poderá apresentar em juízo proposta de prevenção ou reparação de danos a interesses ou direitos difusos, coletivos ou individuais homogêneos, consistente em programa extrajudicial. (...) $\$ 4^{\circ}$ O procedimento poderá compreender as diversas modalidades de métodos alternativos de resolução de conflitos, para possibilitar a satisfação dos interesses e direitos referidos no caput, garantidos a neutralidade da condução ou supervisão e o sigilo.”

16 CALMON, Petrônio. Fundamentos da Mediação e da Conciliação. Rio de Janeiro: Forense, 2007, p. 4. 
Ainda assim, serão desenvolvidas neste trabalho as premissas processuais teóricas que permitem a aproximação entre resolução extrajudicial e tutela coletiva, para que, ao final, possam ser demonstradas as atuais perspectivas à resolução extrajudicial de conflitos coletivos no Brasil.

\section{Questões a serem investigadas}

O presente trabalho propõe-se a investigar a possibilidade, à luz de critérios de admissibilidade e adequação, de utilização de técnicas extrajudiciais para a resolução de conflitos relativos a direitos coletivos.

De um lado, o uso de técnicas alternativas de resolução de controvérsias é uma forte tendência universal no direito processual contemporâneo, diante da percepção da insuficiência quantitativa e qualitativa do processo estatal. De outro, os litígios de feição transindividual são uma das marcas preponderantes da litigiosidade pós-moderna e a inspiração de muitas das reformas processuais que foram implantadas desde a década de 80 e das que são planejadas para o futuro, dentre elas, o projeto de alteração da Lei de Ação Civil Pública e a elaboração de um novo Código de Processo Civil.

Em que pese se tratar de assuntos centrais do direito processual civil atual, o exame da literatura revela que houve poucas tentativas de se estabelecer diálogo entre eles $^{17}$. A rigor, o tema - perspectivas à resolução extrajudicial de conflitos coletivos no Brasil - tem sido tratado apenas como premissa de trabalhos voltados ao exame da natureza jurídica do compromisso de ajustamento de conduta. Há, portanto, vasto campo para pesquisa e teorização.

17 GONÇALVES, Eduardo Damião. Arbitrabilidade objetiva. Tese de Doutorado apresentada à Faculdade de Direito da Universidade de São Paulo, 2008; ALVES, Rafael Francisco. A arbitrabilidade do direito ambiental: a questão da disponibilidade de direitos. In: SALLES, Carlos Alberto de; SILVA, Solange Teles da; NUSDEO, Ana Maria de Oliveira (Org.). Processos Coletivos e Tutela Ambiental. Santos: Editora Universitária Leopoldianum, 2006; LIMA, Bernardo. A arbitrabilidade do Dano Ambiental. São Paulo: Atlas, 2010; GAVRONSKI, Alexandre Amaral. Técnicas Extraprocessuais de tutela coletiva: a efetividade da tutela coletiva fora do processo judicial. São Paul: RT, 2010; FRANGETTO, Flavia Witkowski. Arbitragem Ambiental: Solução de conflitos r(estrita) ao âmbito (inter)nacional? Campinas: Millennium, 2006. 
Neste contexto, a proposta central da presente dissertação é investigar se os conflitos relativos a direitos coletivos estariam limitados à resolução por meio de processo judicial ou se haveria campo, e em que medida, para a resolução extrajudicial.

Para tanto, há diversas questões teóricas a serem analisadas como premissas para o tema proposto, em especial, as modalidades de técnicas de resolução de conflitos, no plano da garantia constitucional de acesso à justiça e os critérios que devem orientar os litigantes na opção pela sua utilização. ${ }^{18}$

Um dos grandes desafios a ser enfrentado nesta dissertação consiste do exame do conceito de disponibilidade e suas repercussões na possibilidade de resolução extrajudicial de conflitos coletivos.

É essencial, para os fins, deste trabalho, responder à indagação de Eduardo Damião GONÇALVES: Será que quando o legislador contemporâneo resolveu proteger determinados interesses, será que ele quis protegê-los e dizer que eles só deveriam ser tutelados ou julgados pelo Poder Judiciário? ${ }^{19}$

Há que se investigar ainda se os legitimados coletivos, autorizados à tutela de direitos coletivos, em juízo, estariam também legitimados - e, em caso afirmativo, em que medida - à resolução extrajudicial.

Ademais, chegando-se à conclusão de que as técnicas extrajudiciais de solução de disputas seriam admissíveis para a resolução de controvérsias que envolvam direitos coletivos, haverá de se analisar, ainda, se tais técnicas são adequadas, isto é, se a sua utilização poderia trazer benefícios, considerando os argumentos supra referidos de produção e de qualidade.

À vista de tal estruturação, a importância do tema central desta dissertação consiste no desenvolvimento dos pilares teóricos que indicam as perspectivas atuais para a resolução alternativa de conflitos coletivos, a fim de que possa ser identificada, nesta seara, a necessariedade da justiça estatal na composição de lides desta natureza.

18 Tais questões foram tratadas no segundo e terceiro capítulos desta dissertação.

19 GONÇALVES, Eduardo Damião. In: GRINOVER, Ada Pellegrini; GONÇALVES, Eduardo Damião. Conferência sobre arbitragem na tutela dos interesses difusos e coletivos. Revista de processo, v. 136, jun. 2006, p. 7, versão eletrônica. 
Por fim, será imprescindível examinar, em termos concretos, como se daria a utilização de técnicas extrajudiciais de resolução de controvérsias, em especial, como poderia se dar o uso da arbitragem, que é a técnica mais formal dentre as técnicas ditas alternativas.

\section{Método de trabalho}

A presente dissertação foi desenvolvida a partir da investigação analítica e dogmática acerca da possibilidade de compatibilização dos dois grandes pilares envolvidos na pesquisa: as técnicas extrajudiciais de resolução de controvérsias e o processo coletivo brasileiro.

Em perspectiva metodológica, a pesquisa foi estruturada em sete capítulos, sendo o primeiro, a introdução do assunto e do tema, e o último, as conclusões finais do trabalho, aportadas ao longo de seu desenvolvimento e indicadas, ao final de cada capítulo, como conclusões parciais. O três capítulos centrais (capítulos segundo, terceiro e quarto) contemplam o desenvolvimento das premissas que foram adotadas na dissertação. Por fim, os capítulos quinto e sexto materializam as conclusões do presente trabalho.

Passa-se, então, ao detalhamento pontual dos temas que serão abordados em cada um dos capítulos.

Após este primeiro capítulo introdutório, será apresentado no segundo capítulo, panorama atual sobre mecanismos extrajudiciais de resolução de disputas, com ênfase na sua inserção no quadro do movimento universal de acesso à justiça e no critério classificatório utilizado por Niceto ALCALÁ-ZAMORA Y CASTILLO.

O terceiro capítulo volta-se à análise das espécies de técnicas de resolução de controvérsias e encerra-se com proposta de sistematização de dois critérios que devem orientar a escolha e utilização de cada uma dessas técnicas: admissibilidade e adequação. Pela proposição, o exame da admissibilidade deve ser aferido a partir de critérios objetivos e subjetivos, enquanto que a análise da adequação perpassa pelo exame das peculiaridades do conflito e dos potenciais resultados a serem produzidos pela utilização de cada técnica, a fim de que se possa aferir a sua especial e concreta aptidão compositiva para o caso. 
Ainda em sede de premissas, serão examinados, no quarto capítulo, conceitos fundamentais ligados à tutela coletiva.

Em primeiro lugar, serão analisadas as características das pretensões de natureza transindividual, a partir da definição de cada uma das espécies de direitos e identificação dos critérios práticos de identificação dos direitos coletivos. A necessidade de perfeita identificação da natureza do direito transindividual foi abordada como pressuposto para a posterior identificação, no plano da admissibilidade, das técnicas extrajudiciais que podem vir a ser utilizadas para a composição de tais litígios.

Em segundo lugar, serão tratadas as regras fundamentais que disciplinam o regime de legitimação e de coisa julgada no processo coletivo.

Em terceiro lugar, serão examinados os aspectos essenciais do compromisso de ajustamento de conduta, em especial a definição de sua natureza jurídica, premissa imprescindível para os fins deste trabalho.

Concluída esta etapa, passa-se, nos capítulos subsequentes, à aplicação dos conceitos e premissas previamente estabelecidas para que se pudesse, enfim, identificar os horizontes e as limitações à resolução extrajudicial de conflitos coletivos.

Com este objetivo, o quinto capítulo volta-se ao exame da admissibilidade e adequação do uso de técnicas alternativas de resolução dos conflitos para a resolução de conflitos que envolvam direitos coletivos.

Quanto ao juízo de admissibilidade, será analisada, sob o prisma objetivo, a possibilidade de enquadramento das espécies de direitos coletivos aos requisitos do cabimento dos mecanismos extrajudiciais e, sob o prisma subjetivo, a capacidade dos legitimados coletivos para representarem tais pretensões ${ }^{20}$ em negociações, mediações, conciliações e arbitragens.

Sobre o juízo de adequação, busca-se abordar, em linhas gerais, a questão da vocação do conflito do coletivo para ser dirimido por meio de técnicas extrajudiciais de resolução de controvérsias.

Por fim, o sexto capítulo trata, sem pretensão exaustiva, das perspectivas atuais e concretas para a resolução extrajudicial de conflitos coletivos no Brasil. Quanto à

20 Não é objeto desta dissertação a análise da capacidade dos legitimados coletivos para representarem os titulares dos direitos coletivos em eventuais pretensões deduzidas em face deles. 
possibilidade de utilização da arbitragem, procurou-se fornecer breve panorama sobre o desenvolvimento das class actions arbitrations nos Estados Unidos, por ser o paradigma mais relevante em termos de processo arbitral relativo a direitos individuais homogêneos ainda que fundado em premissas substancialmente diversas - para que, ao final, sejam assinalados os horizontes à utilização desta técnica, no Brasil, para a resolução de conflitos nesta seara.

No sétimo e último capítulo, serão expostas as conclusões finais do trabalho, construídas ao longo do seu desenvolvimento. 


\section{Capítulo VII - Conclusões}

O atual estágio de desenvolvimento do movimento universal de acesso à justiça recomenda a investigação teórica sobre a possibilidade de resolução extrajudicial de conflitos relativos a direitos coletivos, típicos da litigiosidade pós-moderna.

A nota de indisponibilidade material tradicionalmente associada aos direitos coletivos sem maiores investidas teóricas opera, na teoria, como imposição de cláusula de reserva ao Poder Judiciário, como se somente por meio da intervenção judicial pudesse haver resolução de conflitos dessa natureza.

A investigação das possíveis desembocaduras dos litígios, das espécies de técnicas extrajudiciais de resolução de controvérsias e das características essenciais de cada uma das espécies de direitos coletivos revela, porém, que os conflitos relativos a direitos coletivos estão, em boa medida, imunes à necessariedade da jurisdição estatal.

A análise de critérios de ordem subjetiva autoriza a conclusão de que os órgãos públicos legitimados à tutela coletiva possuem legitimidade e capacidade para que promovam, também, a resolução extrajudicial de conflitos relativos a direitos coletivos. As associações, apesar de legitimadas à tutela coletiva, possuem legitimidade restrita para o pleito de prestação de tutela jurisdicional.

A análise de critérios de ordem objetiva também autoriza a conclusão de que os litígios relativos a direitos essencialmente coletivos podem ser solucionados por meio de técnicas extrajudiciais de resolução de controvérsias, em especial por meio da celebração de compromisso de ajustamento de conduta. A possibilidade de negociação encontra limite apenas no resguardo integral do bem jurídico coletivo ameaçado ou lesionado. Todos os demais aspectos relativos à forma, técnica e prazo de reparação podem ser negociados.

Essa mesma análise de ordem objetiva revela, ainda, que a natureza material indisponível dos direitos coletivos não impede a utilização da arbitragem, uma vez que tais direitos são disponíveis sob a ótica instrumental, pois não estão submetidos à intervenção judicial necessária. A conclusão a que se chega é que os litígios relativos a direitos difusos e coletivos stricto sensu que materializem pretensões de natureza patrimonial, decorrentes, por exemplo, da necessidade de reparação a dano a bem jurídico coletivo, podem ser objeto 
de arbitragem, assim como as pretensões circunscritas à aferição do modo, técnica e prazo a serem observados no cumprimento da obrigação de reparar.

A análise de critérios objetivos de admissibilidade também denota que os litígios relativos a direitos individuais homogêneos também podem ser solucionados por meio de técnicas extrajudiciais de resolução de controvérsias.

À vista da disponibilidade material das pretensões dessa natureza, podem os órgãos públicos firmar compromissos de ajustamento de conduta que não representem a satisfação da integralidade da pretensão que seria deduzida em eventual demanda, desde que a solução obtida seja economicamente interessante para os titulares de direito, considerando-se a probabilidade de êxito da tese, à luz da doutrina e da jurisprudência, o tempo que eventual processo judicial ou arbitral poderia levar até a obtenção de sentença transitada em julgado que reconhecesse a obrigação de ressarcimento dos danos causados.

Ainda assim, como decorrência do próprio sistema legal concebido para a tutela de direitos individuais homogêneos, em especial da regra da coisa julgada secundum eventum litis, a transação celebrado no plano coletivo somente poderia vincular os titulares dos direitos individuais se integralmente favorável ou em caso de expressa aquiescência (opt in).

As técnicas extrajudiciais de resolução de disputas, além de serem cabíveis para a resolução de conflitos relativos a direitos coletivos, também podem ser consideradas técnicas adequadas, à luz de argumentos de produção - resultados a serem obtidos com menor dispêndio de tempo e de recursos - e de argumentos de qualidade - superioridade dos resultados.

Tanto a negociação, quanto a conciliação, técnicas que podem propiciar a resolução consensual de litígios coletivos, revelam-se adequadas por terem aptidão para proporcionar a rápida resolução do conflito, com baixo custo, por meio de uma solução escolhida pelas próprias partes em disputa. Nesta medida, a resolução consensual tende a ser qualitativamente superior à resolução do conflito por meio heterocompositivo, em que a resolução do conflito advém de uma decisão imposta por um terceiro neutro imparcial.

Em paralelo, a arbitragem também pode ser considerada técnica adequada para a resolução de conflitos relativos a direitos coletivos. É pressuposto de sua utilização, porém, que o particular (potencial demandado em eventual ação judicial) esteja disposto a arcar com todos os encargos financeiros da arbitragem, em razão da norma que assegura 
aos legitimados coletivos a isenção de adiantamento de custas, honorários, emolumentos etc, salvo em caso de comprovada má-fé.

Estando o particular de acordo em suportar tais custos, os benefícios que o uso da arbitragem pode trazer são notáveis.

O prazo de tramitação de um processo arbitral tende a ser muito mais exíguo do que o prazo que uma sentença proferida em uma ação coletiva costuma levar para transitar em julgado. Essa economia de tempo configura-se uma especial vantagem, diante das peculiaridades dos bens jurídicos coletivos, em que a pronta reparação é essencial para evitar o agravamento e perpetuação da lesão.

A possibilidade de eleição de árbitro ou tribunal arbitral especializado no tema técnico ou jurídico subjacente ao litígio também eleva as chances de o resultado obtido vir a ser qualitativamente superior àquele que seria alcançado, caso o litígio fosse apreciado por um julgador generalista. Especialmente nas demandas relativas a direitos essencialmente coletivos, que envolvam, por exemplo, temas de direito ambiental e de direito urbanístico, há grande vantagem se o julgador for um especialista na matéria.

Eventual arbitragem para a resolução de conflitos coletivos haveria de ser convencionada por cláusula inserida em compromisso de ajustamento de conduta ou ainda por meio de compromisso arbitral.

A escolha do árbitro haveria de ser feita a partir de critérios objetivos, entre pessoas capazes que desfrutem da confiança de todas as partes.

O procedimento a ser adotado em eventual arbitragem coletiva, via de regra, não poderia ser sigiloso, salvo quando o próprio interesse público recomendar que assim se proceda. 


\section{REFERÊNCIAS}

ABELHA, Marcelo. Ação civil pública e meio ambiente. 2. ed. Rio de Janeiro: Forense Universitária, 2004.

AKAOUI, Fernando Reverendo Vidal. Compromisso de Ajustamento de Conduta Ambiental. 2. ed. São Paulo: RT, 2008.

ALCALÁ-ZAMORA Y CASTILLO, Niceto. Proceso, autocomposición y autodefensa: contribuición al estudio de los fines del proceso. 3. ed. Cidade do México: Universidad Nacional Autónoma de México, 2000.

ALVES, Rafael Francisco. A arbitrabilidade do direito ambiental: a questão da disponibilidade de direitos. In: SALLES, Carlos Alberto de; SILVA, Solange Teles da; NUSDEO, Ana Maria de Oliveira (Org.). Processos Coletivos e Tutela Ambiental. Santos: Editora Universitária Leopoldianum, 2006.

ALVES, Rafael Francisco; GABBAY, Daniela Monteiro; LEMES, Selma Ferreira. Projeto de pesquisa: Arbitragem e Poder Judiciário. Parceria institucional acadêmico-científica da Escola de Direito de São Paulo da FGV e do Comitê Brasileiro de Arbitragem (CBAr). Revista Brasileira de Arbitragem, v. 19, 2008.

AMARAL, Paulo Osternack. Arbitragem e Poder Público: cabimento, aspectos processuais, incidente de suspensão e mandado de segurança. Dissertação apresentada ao programa de pós-graduação stricto sensu em Direito Processual da Faculdade de Direito da Universidade de São Paulo. São Paulo, 2010.

ANDRIGHI, Fátima Nancy. Arbitragem nas relações de consumo: uma proposta concreta. Revista de Arbitragem e Mediação, ano 3, n. 9, abr-jun. 2006.

ANTUNES, Paulo de Bessa. Direito ambiental, indisponibilidade de direitos, solução alternativa de conflitos e arbitragem. Revista de Arbitragem e Mediação, v. 30, jul. 2011.

ARRUDA ALVIM, José Manuel de. Ação Civil Pública. Revista de Processo, v. 87, julset 1997.

AZEVEDO, Antonio Junqueira de. A arbitragem e o Direito do Consumidor. Estudos $e$ Pareceres de Direito Privado. São Paulo: Saraiva, 2004.

BACELLAR, Roberto Portugal. A mediação no contexto dos modelos consensuais de resolução de conflitos. Revista de Processo, ano 24, n. 95, jul-set. 199.

BANDEIRA DE MELLO, Celso Antonio. Curso de Direito Administrativo. 27. ed. São Paulo: Malheiros, 2011.

BARBOSA MOREIRA, José Carlos. A ação popular do direito brasileiro como instrumento de tutela jurisdicional dos chamados "interesses difusos". Temas de Direito Processual. São Paulo: Saraiva, 1977. 
. Coisa julgada e declaração. Temas de direito processual. São Paulo: Saraiva, 1977.

. Eficácia da sentença e autoridade da coisa julgada. Temas de direito processual: terceira série. São Paulo: Saraiva, 1984.

. Notas sobre o problema da "efetividade" do processo. Temas de direito processual: terceira série. São Paulo: Saraiva, 1984.

- Tutela Jurisdicional dos Interesses Coletivos ou Difusos. Temas de Direito Processual: terceira série, 1984.

. Notas sobre el contenido, los efectos y La imutabilidad de la sentencia. Temas de direito processual: quinta série. São Paulo: Saraiva, 1994.

. Privatização do processo? In: Temas de Direito Processual. São Paulo: Saraiva, 2001, sétima série.

. A importação de modelos jurídicos. Temas de Direito Processual: oitava série. São Paulo: Saraiva, 2004.

La definizione di Cosa Giudicata Sostanziale nel Codice di Procedura Civile Brasiliano. Temas de Direito Processual: nona série, São Paulo: Saraiva, 2007.

. Conteúdo e efeitos da sentença: variações sobre o tema. Revista de Processo, n. 40, São Paulo, 1985.

Ainda e sempre coisa julgada. Revista dos Tribunais, n. 416, junho, 1970.

BEDAQUE, José Carlos dos Santos. Direito e Processo: Influência do direito material sobre o processo. 4. ed. São Paulo: Malheiros, 2006.

BEVILAQUA, Clovis. Código Civil dos Estados Unidos do Brasil comentado por Clovis Bevilaqua. Rio de Janeiro: Editora Rio, 1958.

BOTELHO DE MESQUITA, José Ignácio. Na ação do consumidor, pode ser inútil a defesa do fornecedor. Revista do Advogado, São Paulo, n. 33, 1990.

BRAGA NETO, Adolfo. Alguns Aspectos Relevantes sobre a Mediação de Conflitos. In: GRINOVER, Ada Pellegrini. WATANABE, Kazuo; LAGRASTA NETO, Caetano. Mediação e Gerenciamento do Processo. São Paulo: Atlas, 2008.

BUCKNER, Carole J. Due process in Class Arbitration. Florida Law Review, n. 58, 2006.

BUENO, Cassio Scarpinella. Partes e Terceiros no processo civil brasileiro. 2. ed. São Paulo: Saraiva, 2008.

CABRAL, Antonio do Passo. O novo procedimento-modelo (Musterverfahren) alemão: uma alternativa às ações coletivas. Revista de Processo, ano 32, n. 147, maio-2007. 
CAHALI, Francisco José. Curso de Arbitragem: Mediação, Conciliação, Resolução CNJ 125/2010. São Paulo: RT, 2011.

CALAMANDREI, Piero. Instituciones de Derecho Procesal Civil segun el nuevo Codigo. Tradução de Santiago Sentis Melendo. Buenos Aires: Editorial Depalma, 1943.

CALMON DE PASSOS, J. J. Democracia, participação e processo. In: GRINOVER, Ada Pellegrini; DINAMARCO, Candido Rangel; WATANABE, Kazuo. Participação $e$ Processo. São Paulo: RT, 1988.

CALMON, Petrônio. Fundamentos da Mediação e da Conciliação. Rio de Janeiro: Forense, 2007.

CAPPELETTI, Mauro; GARTH, Bryant. Acesso à Justiça. Tradução de Ellen Gracie Northfleet. Porto Alegre: Sergio Antonio Fabris, 1988.

CAPPELLETTI, Mauro. Os métodos extrajudiciais de solução de conflitos no quadro do movimento universal do acesso à justiça. Revista de Processo, ano 19, n. 74, abr-jun 1994.

CARMONA, Carlos Alberto. A arbitragem no processo civil brasileiro. São Paulo: Malheiros, 1993.

CARNEIRO, Paulo Cesar Pinheiro. A proteção dos Direitos Difusos através do Compromisso de Ajustamento de Conduta previsto na Lei que disciplina a Ação Civil Pública (Lei n. ${ }^{\circ} 7.347 / 85$ - artigo $5^{\circ}$, parágrafo $6^{\circ}$ ). Revista da Faculdade de Direito da Universidade Estado do Rio de Janeiro, n. 1, 1993.

CARNELUTTI, Francesco. Instituciones del Proceso Civil. Tradução da quinta edição italiana por Santiago Sentis Melendo. Buenos Aires: Ediciones Juridicas Europa-America, 1973.

CHIOVENDA, Giuseppe. Instituições de Direito Processual Civil. 2. ed. São Paulo: Saraiva, 1965, v. II.

COMOGLIO, FERRI e TARUFFO. Lezioni sul processo civile. 4. ed. Bolonha: Il Mulino, 2006.

CINTRA, Antonio Carlos de Araújo; GRINOVER, Ada Pellegrini; DINAMARCO, Candido Rangel. Teoria Geral do Processo. 26. ed. São Paulo: Malheiros, 2010.

COSTA, Susana Henriques da. In: Lei de Ação Civil Pública e Lei de Ação Popular (Coord.). São Paulo: Quartier Latin, 2006.

O Processo Coletivo na Tutela do Patrimônio Público e da Moralidade Administrativa. São Paulo: Quartier Latin, 2009.

DEMARCHI, Juliana. Técnicas de Conciliação e Mediação. In: GRINOVER, Ada Pellegrini. WATANABE, Kazuo; LAGRASTA NETO, Caetano. Mediação $e$ Gerenciamento do Processo. São Paulo: Atlas, 2008. 
DIEMER, Mary S., Utah to Allow Class Action Waivers in Consumer Credit Agreements. Disponível em http://www.nelsonmullins.com/news/nelson-mullins-articles-speechesdetail.cfm?id=89.

DINAMARCO, Candido Rangel. A instrumentalidade do processo. 12. ed. São Paulo: Malheiros, 2005.

. Direito e Processo. Fundamentos do Processo Civil Moderno. 6. ed. São Paulo: Malheiros, 2010, v. I.

Os institutos fundamentais do direito processual. Fundamentos do Processo Civil Moderno. São Paulo: Malheiros, 2010, v. I.

. Universalizar a Tutela Jurisdicional. Fundamentos do Processo Civil Moderno. São Paulo: Malheiros, 2010, v. I.

. Tutela Jurisdicional. Fundamentos do Processo Civil Moderno. 6. ed. São Paulo: Malheiros, 2010, v. II.

. Instituições de Direito Processual Civil. 3. ed., v. III, São Paulo: Malheiros, 2003.

. Limites da sentença arbitral e de seu controle jurisdicional. Revista jurídica 290/05-

15. Porto Alegre: NOTADEZ, dez. 2001.

DINAMARCO, Pedro da Silva. Ação civil pública. São Paulo: Saraiva, 2001.

DUNHAM, Edward Wood. The Arbitration Clause as Class Action Shield, Franchise Law Journal, n.16, primavera de 1997.

FALECK, Diego. Introdução ao Design de Sistemas de Disputas: Câmara de Indenização 3054. Revista Brasileira de Arbitragem, n. 23, jul-set. 2009.

FARIA, José Eduardo. O Direito na economia globalizada. São Paulo: Malheiros, 2004.

FERNANDES, Rodrigo. Compromisso de Ajustamento de Conduta Ambiental: fundamentos, natureza jurídica, limites e controle jurisdicional. São Paulo: Renovar, 2008.

FERRARESI, Eurico. Ação Popular, Ação Civil Pública e Mandado de Segurança Coletivo: instrumentos processuais coletivos. Rio de Janeiro: Forense, 2009.

FIELD, Richard; KAPLAN, Benjamin; CLERMONT, Kevin M. Materials for a Basic Course in Civil Procedure. 7. ed. Westbury: The Foundation Press, Inc., 1997.

FIGUEIRA JÚNIOR, Joel Dias. Arbitragem, Jurisdição e Execução. 2. ed. São Paulo: RT, 1999.

FINK, Daniel Roberto. Alternativa à ação civil pública ambiental (reflexões sobre as vantagens do termo de ajustamento de conduta). In: MILARÉ, Edis. Ação Civil Pública: Lei 7.347/1985 - 15 anos. 2. ed. São Paulo: RT, 2002. 
FISCHER, Robert; URY, William; PATTON, Bruce. Como chegar ao sim - a negociação de acordos sem concessões. Trad. Vera Ribeiro e Ana Luiza Borges. 2. ed. Rio de Janeiro: Imago, 2005.

FISS, Owen. Contra o acordo. Um novo processo civil. Tradução de Carlos Alberto de Salles. São Paulo: RT, 2004.

FISS, Owen; RESNIK, Judith. Adjudication and its alternatives: An Introduction to Procedure. Nova Iorque: Foundation Press, 2003.

FRANGETTO, Flavia Witkowski. Arbitragem Ambiental: Solução de conflitos r(estrita) ao âmbito (inter)nacional? Campinas: Millennium, 2006.

FREITAS, Vladimir Passos de; FREITAS, Mariana Almeida Passos de. Conciliação, execução e efetividade nas ações civis públicas. In: MILARÉ, Édis. A ação civil pública após 25 anos. São Paulo, RT, 2010.

GABBAY, Daniela Monteiro. Negociação. In: PELUSO, Antonio Cezar; RICHA, Morgana de Almeida (coord.). Conciliação e mediação: estruturação da política judiciária nacional. Rio de Janeiro: Forense, 2011.

GALANTER, Marc. Introduction: Compared to what? Assessing the quality of dispute processing. Denver University Law Review, n. 66, 1989

GAVRONSKI, Alexandre Amaral. Técnicas Extraprocessuais de tutela coletiva: a efetividade da tutela coletiva fora do processo judicial. São Paulo: RT, 2010.

GIDI, Antonio. A Class Action como instrumento de tutela coletiva dos direitos: As ações coletivas em uma perspectiva comparada. São Paulo: RT, 2007.

. Coisa Julgada e Litispendência nas Ações Coletivas. São Paulo: Saraiva, 1995.

Rumo a um Código de Processo Civil Coletivo: A codificação das ações coletivas no Brasil. Rio de Janeiro: Forense, 2008.

GOMES, Orlando. Contrato de Adesão: Condições Gerais dos Contratos. São Paulo: RT, 1972.

GONÇALVES, Eduardo Damião. Arbitrabilidade objetiva. Tese de Doutorado apresentada à Faculdade de Direito da Universidade de São Paulo, 2008.

GONÇALVES, Eduardo Damião. In: GRINOVER, Ada Pellegrini; GONÇALVES, Eduardo Damião. Conferência sobre arbitragem na tutela dos interesses difusos e coletivos. Revista de processo, v. 136, jun. 2006.

GRINOVER, Ada Pellegrini. Os fundamentos da justiça conciliativa. In: GRINOVER, Ada Pellegrini. WATANABE, Kazuo; LAGRASTA NETO, Caetano. Mediação $e$ Gerenciamento do Processo. São Paulo: Atlas, 2008. 
- Deformalização do processo e Deformalização das controvérsias. Novas Tendências do Direito Processual de acordo com a Constituição de 1988. Rio de Janeiro: Forense Universitária, 1990.

- Da Class Action For Damages à Ação de Classe brasileira: Os Requisitos de Admissibilidade. O Processo: Estudos \& Pareceres. São Paulo: Perfil, 2005.

Eficácia e Autoridade da Sentença: A Teoria de Liebman no Código de Defesa do Consumidor e no Código Modelo de Processos Coletivos para Ibero-América. O Processo: Estudos e Pareceres. São Paulo: Perfil, 2005.

A conciliação extrajudicial no quadro participativo. In: GRINOVER, Ada Pellegrini; DINAMARCO, Candido Rangel; WATANABE, Kazuo. Participação $e$ Processo. São Paulo: RT, 1988.

Ações coletivas para a tutela do ambiente e dos consumidores: Lei 7.347, de 24.7.85. Revista de Processo, São Paulo, n. 44, p. 117, out./dez. 1986.

GUEDES, Clarissa Diniz. Legitimidade Ativa e Representatividade na Ação Civil Pública. Rio de Janeiro, GZ Editora, 2012.

HANOTIAU, Bernard. A New Development in Complex Multiparty-Multicontract Proceedings: Classwide Arbitration. Arbitration International, London Court of International Arbitration, v. 20, n. 1, 2004.

HAZARD JR, Geoffrey C; TARUFFO, Michele. American Civil Procedure: an Introduction. New Haven: Yale University Press, 1993.

HIGHTON, Elena; ÁLVAREZ; Gladys S. Mediación para resolver conflictos. 2. ed. Buenos Aires: Ad-Hoc, 1996.

JUSTEN FILHO, Marçal. Curso de Direito Administrativo. 4. ed. São Paulo: Saraiva, 2009.

KANE, Mary Kay. Civil Procedure in a Nutshell. 4. ed. St. Paul: West Publishing Company, 1996.

LEMES, Selma Ferreira. Arbitragem na Administração Pública: fundamentos jurídicos e eficiência econômica. São Paulo: Quartier Latin, 2007.

LEMOS, Patrícia Faga Iglecias. Meio Ambiente e Responsabilidade Civil do Proprietário: análise do nexo causal. São Paulo: RT, 2008.

LENZA, Pedro. Teoria Geral da Ação Civil Pública. 3. ed. São Paulo: RT, 2008.

LEONEL, Ricardo de Barros. Manual do Processo Coletivo. 2. ed. São Paulo: RT, 2011.

Reclamação Constitucional. Tese apresentada ao concurso de livre-docência do Departamento de Direito Processual da Universidade de São Paulo. São Paulo, 2010. 
LIEBMAN, Enrico Tullio. Eficácia e Autoridade da Sentença e outros Escritos sobre a Coisa Julgada. 4. Ed. Rio de Janeiro: Forense, 2007.

LIMA, Bernardo. A arbitrabilidade do Dano Ambiental. São Paulo: Atlas, 2010.

LOPES, José Reinaldo de Lima. Direitos Sociais: Teoria e prática. São Paulo: Método, 2006.

A definição do interesse público. In: SALLES, Carlos Alberto (Org.). Processo civil e interesse público: o processo como instrumento de defesa social. São Paulo: RT, 2003.

LORENCINI, Marco Antônio Garcia Lopes. Prestação jurisdicional pelo Estado e meios alternativos de solução de controvérsias: convivência e formas de pacificação social. Uma sugestão de integração. Tese apresentada ao programa de pós-graduação stricto sensu em Direito Processual da Faculdade de Direito da Universidade de São Paulo. São Paulo, 2006

LUCHIARI, Valeria Ferioli Lagrasta. A resolução n. 125 do Conselho Nacional de Justiça: Origem, Objetivos, Parâmetros e Diretrizes para a Implantação Concreta. In: PELUSO, Antonio Cezar; RICHA, Morgana de Almeida (coord.). Conciliação e mediação: estruturação da política judiciária nacional. Rio de Janeiro: Forense, 2011.

MALUF, Carlos Alberto Dabus. A Transação no Direito Civil e no Processo Civil. 2. ed. São Paulo, 1999.

MANCUSO, Rodolfo de Camargo. A resolução dos conflitos e a função judicial. São Paulo: RT, 2010.

Interesses Difusos: conceito e legitimação para agir. 5. ed. São Paulo: RT, 2000. . Jurisdição coletiva e Coisa Julgada. São Paulo: RT, 2006.

MARINONI, Luiz Guilherme; ARENHART, Sergio Cruz. MARINONI, Luiz Guilherme; ARENHART, Sergio Cruz. Curso de Processo Civil. São Paulo: Revista dos Tribunais, 2006, v. 1.

MARTINS, Pedro A. Batista. Apontamentos sobre a Lei de Arbitragem. Rio de Janeiro: Forense, 2008

MATTOS NETO, Antonio José de. Direitos patrimoniais disponíveis e indisponíveis à luz da Lei da Arbitragem. Revista de processo, v. 122, abr. 2005.

MAZZILLI, Hugo Nigro. Compromisso de ajustamento de conduta - Análise à luz do Anteprojeto do Código Brasileiro de Processos Coletivos. In: GRINOVER, Ada Pellegrini.

MEIRELLES, Hely Lopes. Direito Administrativo Brasileiro. 37. ed. São Paulo: Malheiros, 2011.

MENDES, Aluisio Gonçalves de Castro. Ações coletivas no Direito Comparado e Nacional. 2. ed. São Paulo: RT, 2010. 
MENDES, Aluisio Gonçalves de Castro; WATANABE, Kazuo. Direito Processual Coletivo e o anteprojeto de Código Brasileiro de Processos Coletivo. São Paulo: RT, 2007.

MEROI, Andrea A. Procesos Colectivos: recepción y problemas. Santa fe: RubinzalCulzoni, 2008.

MILARÉ, Édis. O compromisso de ajustamento de conduta e o fundo de defesa de direitos difusos: relação entre os instrumentos alternativos de defesa ambiental da Lei 7.347/1985. Revista de Direito Ambiental, v. 38, abr. 2005.

NERY JR, Nelson. In: GRINOVER, Ada Pellegrini et alii. Código Brasileiro de Defesa do Consumidor comentado pelos Autores do Anteprojeto. 9. ed. Rio de Janeiro: Forense Universitária, 2007.

. Compromisso de ajustamento de conduta: solução para o problema da queima da palha da cana-de-açúcar. Revista dos Tribunais, v. 692, jun. 1993.

NERY, Ana Luiza de Andrade. Compromisso de Ajustamento de Conduta: Teoria e análise de casos práticos. São Paulo: RT, 2010.

NORONHA. Legal Dictionary. 6. ed. São Paulo: Observador Legal Editora, 2006.

PINHO, Humberto Dalla Bernardina de. Teoria Geral da Mediação. Rio de Janeiro: Lumen Juris, 2008.

PROENÇA, Luis Roberto. Inquérito Civil. São Paulo: RT, 2001.

PUOLI, José Carlos Baptista. Responsabilidade Civil do Promotor de Justiça na tutela aos interesses coletivos: meio ambiente, consumidor, improbidade administrativa. São Paulo: Juarez de Oliveira, 2007.

RICCI, Edoardo F. Desnecessária Conexão entre Disponibilidade do Objeto da Lide e Admissibilidade da Arbitragem: Reflexões Evolutivas. In: LEMES, Selma; CARMONA, Carlos Alberto; MARTINS, Pedro Batista. Arbitragem: Estudos em Homenagem ao Prof. Guido Fernando Silva Soares, In Memoriam. São Paulo: Atlas, 2007.

RODRIGUES, Geisa de Assis. Ação civil pública e Termo de ajustamento de conduta: teoria e prática. Rio de Janeiro: Forense, 2006.

RODRIGUES, Marcelo Abelha. Processo Civil Ambiental. São Paulo: RT, 2008.

SALLES, Carlos Alberto de. Arbitragem em Contrato Administrativos. Rio de Janeiro: Forense; São Paulo: Método, 2011.

Execução judicial em matéria ambiental. São Paulo: RT, 1998.

Mecanismos extrajudiciais de solução de controvérsias e acesso à justiça: a inafastabilidade da tutela jurisdicional recolocada. In: FUX, Luiz; NERY JR, Nelson; 
WAMBIER, Teresa Arruda Alvim (coords). Processo e Constituição: Estudos em Homenagem ao Professor José Carlos Barbosa Moreira. São Paulo: RT, 2006.

- Processo civil de interesse público. In: SALLES, Carlos Alberto (Org.). Processo civil e interesse público: o processo como instrumento de defesa social. São Paulo: RT, 2003.

SCANLON, Kathleen M. Class Arbitration Waivers: The "Severability" Doctrine and Its Consequences. Dispute Resolution Journal, fev-abr. 2007.

SHIMURA, Sérgio. Tutela Coletiva e sua efetividade. São Paulo: Método, 2006.

SILVA, Paula Costa e. A Nova Face da Justiça: os meios extrajudiciais de resolução de controvérsias. Lisboa: Coimbra Editora, 2009.

STERNLIGHT, Jean. R. "As mandatory binding arbitration meets the class action, will de class action survive?" William and Mary Law Review, v. 42, ano 2000.

TALAMINI, Eduardo. Coisa Julgada e sua Revisão. São Paulo: RT, 2005.

A arbitragem e a parceria público-privada (PPP). In: TALAMINI, Eduardo; JUSTEN, Monica Spezia. Parcerias Público-Privadas. São Paulo: RT, 2005.

A (in)disponibilidade do interesse público: consequências processuais (composições em juízo, prerrogativas processuais, arbitragem e ação monitória). Revista de processo, v. 128, out. 2005.

TARTUCE, Fernanda. Mediação nos Conflitos Civis. Rio de Janeiro: Forense, 2008.

- Vulnerabilidade como critério legítimo de desequiparação no processo civil. Tese apresentada ao programa de pós-graduação stricto sensu em Direito Processual da Faculdade de Direito da Universidade de São Paulo. São Paulo, 2011.

TEPEDINO, Gustavo; BARBOZA, Heloisa Helena; MORAES, Maria Celina Bodin de. Código Civil Interpretado conforme a Constituição da República. São Paulo: Renovar, 2006, v. II.

VIEIRA, Fernando Grella Vieira A transação na esfera da tutela dos interesses difusos $e$ coletivos: compromisso de ajustamento de conduta. In: MILARÉ, Edis. Ação Civil Pública: Lei 7.347/1985 - 15 anos. 2. ed. São Paulo: RT, 2002.

WATANABE, Kazuo. In: GRINOVER, Ada Pellegrini. WATANABE, Kazuo; LAGRASTA NETO, Caetano (coord.). Mediação e Gerenciamento do Processo. São Paulo: Atlas, 2008

In: GRINOVER, Ada Pellegrini; BENJAMIN, Antonio Herman de Vasconcellos e; FINK, Daniel Roberto; et alli. Código Brasileiro de Defesa do Consumidor Comentado pelos Autores do Anteprojeto. 9. ed. Rio de Janeiro: Forense Universitária, 2007. 
WESTON, Maureen A. Universes colliding: The Constitutional Implications of Arbitral Class Action. William and Mary Law Review, n. 47, 2005-2006.

YARSHELL, Flávio Luiz. Antecipação da prova sem o requisito da urgência e direito autônoma à prova. São Paulo: Malheiros, 2009.

ZANETI JR, Hermes. Processo Coletivo. Salvador: Juspodivm, 2006. 